\title{
O Autoconceito do Adolescente deficiente Auditivo e sua RelaÇão COM O USO DO APARELHO DE AMPLIFICAÇÃO SONORA INDIVIDUAL
}

\author{
HEARING IMPAIRED ADOLESCENTS' SELF-CONCEPT AND THEIR RELATIONS TO \\ HEARING AIDS
}

\author{
Ana Paula ZUGLIANI ${ }^{1}$ \\ Telma Flores Genaro MOTTI2 \\ Rosicler Moreno CASTANHO ${ }^{3}$
}

\begin{abstract}
RESU M O : para o adolescente com deficiência auditiva, o processo deformação da identidade tem nuances próprias. Além do conflito específico da fase, el etem queformar sua identidade como pessoa que possui uma perda auditiva eque necessita usar aparel ho de amplificação sonora individual (AASI). Considerando que os fatores queinfluenciam o uso desse recurso são inúmeros, estetrabal ho tevepor objetivo verificar a relação do autoconceito do adolescente deficiente auditivo (DA) com o uso do AASI, a partir da percepção do próprio adolescentee deseus pais. A Escala deAutoconceito - EACIJ - equestionários foram aplicados a 30 adolescentes deficientes auditivos, com idades de 12 a 16 anos, em tratamento no Centro deDistúrbios da A udição, Linguagem e Visão (CEDALVI) do HRAC/ USP ea seus pais. Os resultados mostraram que a maioria dos adolescentes estudados faz uso efetivo de seu AASI e tem autoconceito positivo. Concluiu-se que o uso constante desse recurso está associado às boas condições do autoconceito e ao suporte psicossocial da equipe multi / interdisciplinar.
\end{abstract}

PA LA V RA S-CH A VE: autoconceito; adolescência; deficiência auditiva; educação especial .

A BSTRACT: for adolescents who have hearing impairment, theidentity formation process has its own subtleties. Besides the conflicts which are a part of being a teenager, he/ she has to form his/ her identity as someone who has a hearing loss and needs a hearing aid. Taking into account the countl ess factors influencing the use of this resource, this study aimed to undercover the relations between self-concepts of deaf adolescents to the use of hearing aid, looking at the adolescents' own perceptions and those of his parents. The Self-concept Scale EACIJ - and questionnaires were applied to 30 hearing impaired adolescents, aged 12-16years, undergoing treatment at the Centro de Distúrbi os da Audição, Linguagem e Visão (CEDA LVI), a service center within the HRAC/ USP, and to their parents. Theresults showed that most of the subjects involved in thestudy actually use their hearing aids and have positiveself-concept. It was concluded that the constant use of this resource is associated with the good conditions of the self-concept and to the psycho-social support of the multi / interdisciplinary team.

KEYWO R D S: self-concept; adolescence; hearing impai rment; special education.

\footnotetext{
${ }^{1}$ Psicóloga, especialização em Psi cologia Clínica pelo Centro de Distúrbios da A udição, Linguagem eVisão (CEDALVI) do Hospital de Reabilitação deA nomalias Craniofaciais da Universidadede São Paulo (HRAC/ USP), Bauru/ SP.

${ }^{2}$ Doutora em Educação Especial pela UniversidadeFederal deSão Carlos (UFSCar), São Carlos, eDiretora Técnica de Serviço do CEDALVI/ HRAC/ USP, Bauru/ SP - tel motti@centrinho.usp.br

${ }^{3}$ M estre em Educação pela Universidade Estadual Paulista (UNESP), M arília-SP. Psicóloga do CEDALVI/ HRA C/ USP, Bauru-SP - rosecastanho@hotmail.com
} 


\section{InTROdUÇão}

A dolescer, do latim adolescere, significa crescer, desenvolver, atingir a adolescência, e é neste período que vai ocorrendo a passagem da infância para vida adulta (FONSECA et al., 2001).

A adolescência éuma fase considerada bastanteconflituosa, uma etapa de desorganização e instabilidade emocional, caracterizada pelo processo biopsíquico a quea criança, queadentra a juventude, está destinada. N esse período de tempo que caracteriza a adolescência, são observadas modificações em pelo menos três áreas: no corpo, na mentee no ambiente.

De acordo com A berastury e Knobel (1981), tanto as modificações corporais incontroláveis como os imperativos do mundo externo, que exigem do adolescente novas formas de convivência, são vividos, no começo, como uma invasão. O adolescentedesorganiza os aspectos desua personalidade para organizar sua identidade, pois não se trata de uma criança e ainda não ingressou na idade adulta eisto gera conflitos.

Para Serrão e Baleeiro (1999), é certo que a adolescência éum período quemerece atenção ecuidado, principalmente dos pais, educadores eprofissionais desaúde.

A formação da identidade exige a aplicação degrande parteda energia do indivíduo, sendo o autoconceito um importante componente para o processo de identificação do adolescente. $\mathrm{Na}$ adolescência, vivenciada pelo deficiente auditivo, há a possibilidade de agravamento das tensões, devido aos problemas que afetam sua comunicação e entendimento com o ambiente, em geral composto por indivíduos ouvintes.

Para o adolescente deficiente auditivo, o processo de formação da identidade tem nuances próprias, de modo que, além do conflito específico da fase, eletem queformar suaidentidadecomo pessoaquepossui uma perda auditiva. O autoconceito exerce papel fundamental nesse processo, pois o adolescente só vai definir quem ele é e formar uma identidade a partir da visão que tem de si mesmo, ou seja, de seus aspectos negativos e positivos.

O autoconceito é considerado uma organização hierárquica e multidimensional de um conjunto de percepções acerca desi próprio. O conteúdo dessas percepções, isto é, tudo aquilo queo indivíduo reconhececomo partedesi, éadaptável eregulado pelo dinamismo individual, pelas características da interação social epelo contexto situacional (TAMAYO, 1981). A ssim, o autoconceito reflete uma visão mais racional desi próprio.

Segundo Branden (2000), nosso autoconceito équem eo que, consciente ou inconscientemente, achamos quesomos, ou seja, nossas características físicas e psicológicas, pontos positivos e negativose, acima detudo, a auto-estima, queéo componenteavaliador do autoconceito. 
Portanto, o autoconceito compreende um conjunto de percepções, sentimentos, imagens, auto-atribuições e juízos de val ores referentes a si mesmo, envolvendo funções perceptivas eativas e implicand o na participação do indivíduo para defendêlo, conservá-lo e desenvolvê-lo. Desse modo, o autoconceito é fundamentalmente dinâmico, está sempre inacabado, continuamente em construção e cotidianamenteem revisão eadaptação às exigências sociais.

Para Sánchez eEscribano (1999), o autoconceito influi na relação com os outros, consistindo em um fenômeno social, uma vez quea partir das imagens refletidas pelo outro é que o indivíduo se descobre, se estrutura e se reconhece.

O autoconceito também determina a trajetória do indivíduo, poisavisão mais profunda quetem desi influencia todas as escolhas significativas eas decisões, determinando o tipo de vida que o mesmo cria para si.

Devido a essa multiplicidade de fatores, o autoconceito vem sendo considerado, na literatura, um constructo multidimensional que envolve diversos aspectos afetivo-emocionais (BRANDEN , 2000).

O Centro deDistúrbios da Audição, Linguagem eVisão (CEDALVI), serviço do Hospital de Reabilitação de Anomalias Craniofaciais (HRAC), da Universidade de São Paulo (USP), atende pacientes com deficiência auditiva e visual, com o objetivo de proporcionar aos mesmos condições de habilitação, reabilitação e integração, por meio de atendimento especializado, diagnóstico, encaminhamento terapêutico e/ ou indicação e adaptação do Aparelho de A mplificação Sonora Individual (AASI), através de uma equipe multidisciplinar (MOTTI, 2000).

De acordo com Almeida elório (2003), a prótese auditiva, embora seja apenas um dos componentes no tratamento do deficiente auditivo, é a pedra fundamental dos processos de habilitação ereabilitação auditiva.

A experiência clínica no Setor de Psicologia do CEDALVI, nos atendimentos aos adolescentes com deficiências auditivas, tem mostrado que o uso do AASI muitas vezes é interrompido ou prejudicado justamente na fase da adolescência até mesmo quando criança esse aparel ho já foi usado efetivamente, na fase da criança.

Com a entrada na adolescência, esse recurso, embora necessário, tornase uma grande preocupação para o indivíduo. A atitude deescondêlo edeinsistir na adaptação de um aparel ho de tamanho reduzido, dá indícios do desejo de sua ocultação. Ainda assim, existem adolescentes que não prescindem de seu uso visto o benefício obtido, preferindo enfrentar qualquer situação, mesmo as que os façam parecer "diferentes".

De acordo com Fonseca et al. (2001), a percepção de si mesmo como diferente podeser uma experiência difícil para o adolescente. Os autores lembram quea adolescência éuma fase da vida em queseobserva uma certa homogeneização 
entre os jovens, que sefazem parecidos para se sentirem parte do grupo. O modo de se vestir, os hábitos, a identificação com determinados ritmos musicais e as gírias utilizadas tornam-se semelhantes entre os jovens, nos diferentes grupos sociais. N esse contexto, carregar uma diferença pode se tornar penoso nessa fase naturalmentemarcada por conflitos.

Às situações emocionais de lidar com a aceitação da deficiência e do conceito sobresi mesmo, soma-sea necessidade de uso do recurso de amplificação sonora. O mais comum desses recursos, utilizado no tratamento do deficiente auditivo ainda éo AASI, em modelo retroauricular, queseencaixa atrás da orelha. Dessa forma, sea deficiência auditiva não évisível deimediato, o uso do AASI faz com que ela seja notada.

Almeida e Iorio (2003) afirmam que a prótese auditiva tem como final idade primária a amplificação sonora da forma mais adequada e satisfatória possível, sendo o instrumento utilizado para facilitar a educação e o desenvolvimento psicossocial e intel ectual do deficiente auditivo. Nesse sentido, para Fonseca et al. (2001), os aparel hos são "a marca da deficiência”, despertam curiosidade e colocam o usuário em evidência, de modo que seu uso influencia o autoconceito do indivíduo.

Há duas reações típicas que podem ser observadas no adolescente deficiente auditivo: a de evidenciar sua surdez logo no primeiro contato com um desconhecido, anunciando sua diferença, ou tentar escondêla o máximo possível, às vezes evitando o convívio e se isolando.

Na adolescência, assim como na infância, a família representa um papel fundamental na vida do indivíduo, influenciado pelas atitudes dos pais, que constituem seu model o de identificação. Para Sánchez eEscribano (1999), os pais desempenham um papel central na formação do autoconceito do filho.

Bevilacqua eFormigoni (1998) ressaltam que o envolvimento familiar é determinante para os resultados do processo de reabilitação e, por isso, é importante que as pessoas envolvidas com o deficiente auditivo tenham, além de conhecimento do problema, persistência e entusiasmo.

\section{Bjetivo}

O objetivo deste trabal ho foi verificar a relação do autoconceito do adolescente deficiente auditivo com o uso do AASI, a partir da percepção dos próprios adolescentes e de seus pais.

\section{Material e método}

O presente estudo foi aprovado pelo Comitê de Ética em Pesquisa do HRAC/ USP, deacordo com o ofício 352/ 2006-SVAPEPE-CEP, edesenvolvido no 
Setor de Psicologia do Centro de Distúrbios da Audição, Linguagem e Visão (CEDALVI), do HRAC/ USP, em Bauru/ SP, em ambienteadequado para tal .

Participaram da pesquisa 30 adolescentes deficientes auditivos (DA) e seus pais. Os adolescentes tinham idades de 12 a 16 anos, sendo $13(43 \%)$ do sexo masculino e 17 (57\%) do sexo feminino (figura 1). Em relação à condição auditiva, $40 \%$ apresentavam perda profunda bilateral, $30 \%$ perda de severa à profunda bilateral, 13\% perda moderada bilateral e 17\% tinham outros graus de perda (figura 2). Essa última classificação foi baseada nos resultados audiológicos diferentes para as duas orel has, como por exemplo, leveà severa à direita emoderada à esquerda. Todos os adolescentes residiam em Bauru eregião eeram matriculados eatendidos noCEDALVI.

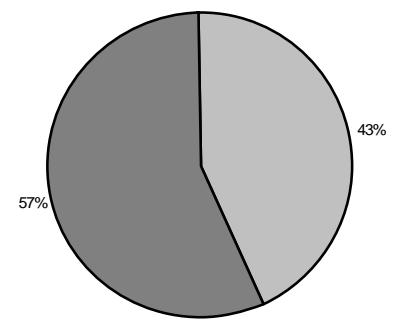

$\square$ Masculino

$\square$ Feminino

Figura 1 - Distribuição dos adolescentes DA quanto ao sexo

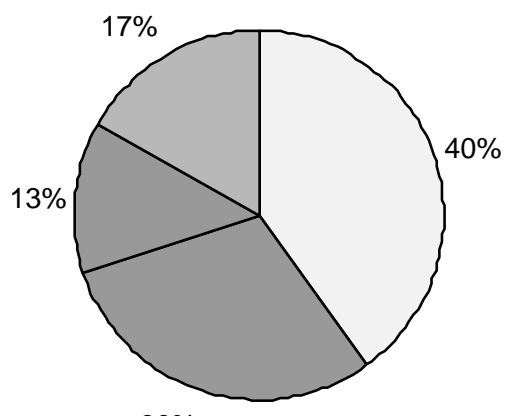

$\square$ Profunda Bilateral

$\square$ Severa à profunda Bilateral

$\square$ Moderada Bilateral

$\square$ Outros Graus de Perda

Figura 2 - Distribuição dos adolescentes DA quanto ao grau da perda auditiva

Os pais e adolescentes DA foram informados sobre os objetivos, final idades e contribuições da pesquisa e orientados sobre a livre escolha de sua participação, sem prejuízo à continuidade do tratamento. Através da Carta de Informação ao Sujeito e do Termo de Consentimento LivreEsclarecido, autorizaram, por escrito, sua participação na pesquisa. 
A Escala de Autoconceito Infanto-juvenil - EAC-IJ (SISTO; MARTINELLI, 2004), que permiteavaliar os diferentes níveis de autoconceito da criança e do jovem, nos contextos sociais com os quais interage freqüentemente, foi aplicada aos adolescentes DA. Esseinstrumento fornece avaliações distintas de quatro ambientes: pessoal, social, familiar e escolar e, também, uma medida de autoconceito geral, que consiste na soma desses quatro. Os resultados consistem em percentis cal culados para cada subescal a eanal isados deacordo com as normas da EAC-IJ, por idade, gênero e faixa de classificação (25\%,50\%, 75\% e intermediárias).

Para interpretação das respostas, quanto maior a pontuação, melhores as condições do autoconceito do indivíduo e vice versa. Desse modo, foi possível verificar as áreas nas quais os adolescentes possuíam maiores facilidades e dificuldades.

Um questionário fechado também foi aplicado aos adolescentes DA (Quadro 1), abordando sentimentos relacionados à deficiência auditiva, uso do AASI eautoconceito.

Concomitantemente foi aplicado um questionário semi-aberto aos pais (Quadro 2), contendo questões sobre o uso do AASI pelo adolescente e sobre a percepção da família a respeito da deficiência auditiva e do uso do aparelho.

Durante a fase de coleta de dados, contou-se com o apoio de um intérpretecom domínio na Língua Brasileira deSinais (LIBRAS), visando facilitar a compreensão pelo DA. O colaborador foi previamentetreinado eorientado quanto ao sigilo a confidenciailidadee às questões éticas pertinentes ao estudo, bem como à neutral idade enão interferência nas respostas.

A análise dos dados deu-se de forma quanti-qualitativa, tendo em vista a pontuação obtida de acordo com as alternativas assinaladas na escala de autoconceito eno questionário dos adolescentes. Quanto ao questionário aplicado aos pais, as respostas às perguntas abertas foram categorizadas e tabuladas. Posteriormente, os achados dos dois questionários foram comparados aos resultados da escala de autoconceito.

\section{Resultados e discussões}

Os resultados da avaliação obtidos na Escala de A utoconceito InfantoJuvenil - EACIJ (SISTO; MARTINELLI, 2004), aplicada aos adolescentes deficientes auditivos e dos questionários aplicados a eles eaos pais, foram organizad os quanto ao autoconceito equanto ao uso do AASI, sendo apresentados a seguir.

\subsection{Q Uanto a o autoconceito}

A aplicação da EACIJ (SISTO; MARTINELLI, 2004) foi realizada de acordo com as subescal as de autoconceito e os resultados foram distribuídos da 
seguinte forma: pontuação alta, quando as respostas dos adolescentes DA foram assinaladas compreendendo a classificação de menos $75 \%$, 75\% e mais $75 \%$; pontuação mediana para as respostas classificadas em menos 50\% e $50 \%$ e pontuação baixa representada pela classificação de menos $25 \%$ e $25 \%$ da escala.

Os resultados obtidos em cada subescala: pessoal, escolar, familiar, social egeral são apresentados na figura 3, a seguir:

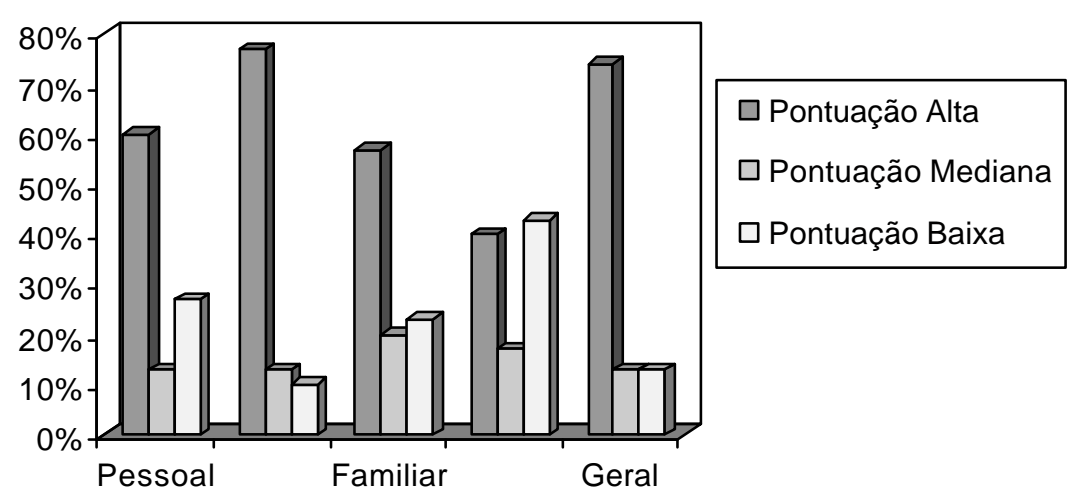

Figura 3- Resultados da A plicação da Escala de A utoconceito I nfanto-Juvenil

0 autoconceito pessoal, deacordo com Sisto e Martinelli (2004), refere-se aos sentimentos que a pessoa tem em relação ao seu modo deser eagir em diferentes situações. Os adol escentes DA obtiveram $60 \%$ deal ta pontuação em relação a este autoconceito, o que significa que se vêem de forma positiva e adotam boas estratégias deenfrentamento eresolução de problemas. Pontuações medianas foram obtidas por $13 \%$ dos indivíduos avaliados, sugerindo autoconceito satisfatório, enquanto que $27 \%$ obtiveram pontuações baixas, indicando queesses adolescentes seavaliam como preocupados, nervosos e com medos.

Segundo Branden (2000), o autoconceito determina a trajetória do indivíduo, exercendo influência nas escolhas e decisões. Dessa forma, éesperado que, para a maior parte dos adolescentes estudados, não haja conseqüências relevantes da deficiência auditiva no tipo de vida queeles criam para si. No entanto, aqueles que obtiveram menor pontuação, resultado que pode ser justificado por uma fase de conflitos (ABERASTURY; KN OBEL, 1981), mostram quenecessitam de um apoio maior, o qual pode vir de profissionais especial izados e da própria família, deacordo com as consi derações de Serrão e Baleeiro (1999).

O autoconceito escolar trata dequestões relativas às relações interpessoais 
que ocorrem no contexto escolar (SISTO; MARTINELLI, 2004). Para Fonseca et al . (2001), na escola o jovem vive muitas desuas experiência longe do ambientefamiliar e pode aprender alidar com suas dificuldades.

N esta subescala, $77 \%$ dos adolescentes obtiveram elevadosíndices de autoconceito, o queleva a supor que se sentem com boa capacidade intelectual e aceitos pelos colegas de classe. Em 13\% dos casos, as pontuações foram medianas eem $10 \%$, pontuações rebaixadas, o que podesignificar que estes seavaliam como não muito espertos para o estudo e rejeitados pelos colegas de escola.

É provável que os bons índices do autoconceito nessa área sedevama uma rededeapoio formada pelos col egas de sala de aula, à interação positiva com o professor, bem como ao suporte da família. Além disso, o autoconceito desempenha um papel importante no processo educativo, conforme Sánchez e Escribano (1999), isto é, o rendimento dos alunos na escola éinterrelacionado com o que sabem, assim como com suas atitudes emotivação. Diante disso, os resultados mostram quena maioria dos casos pode ser esperado um bom entrosamento escolar, com possibilidades de desempenho satisfatório.

Sisto e Martinelli (2004) relatam que oautoconceito familiar refere-se ao comportamento adotado nas situações do dia-a-dia em casa, com os pais eirmãos. A família do deficiente auditivo, de acordo com Fonseca et al. (2001), possui características próprias, já queexperimenta todo um processo, desde o recebimento do diagnóstico atéa suposta aceitação do filho. Para Sánchez eEscribano (1999), quanto maior a aceitação, o afeto, a acolhida eo interesse demonstrados pel os pais a seus filhos, melhor é a imagem que a criança faz de si mesma, sendo que as atitudes democráticas dos pais favorecem o autoconceito positivo.

Na adolescência, para o indivíduo com deficiência auditiva queainda está às voltas com suas limitações de linguagem, o reconhecimento de si mesmo ou de seu processo deaprendizagem, enquanto diferentee o apoio da família, por meio de uma presença constante, são fundamentais, embora, para seu crescimento, seja necessário al gum afastamento (FONSECA et al., 2001). O suporte da família e o acesso ao atendimento profissional especial izado, que consiste em orientação e aconsel hamento aos pais do deficienteauditivo, são fundamentais edecisivos, como mencioam Bevilacqua eFormigoni (1998).

O autoconceito familiar avaliado junto aos adolescentes DA mostrou $57 \%$ de resultados com altos índices, revelando que estes se sentem aceitos no meio familiar, enquanto que $20 \%$ deles obtiveram pontuações medianas e $23 \%$, baixas pontuações. N essecontexto, os al tosíndices obtidos na maior partedos casos indicam bom relacionamento dos sujeitos aval iados com os irmãos, bem como percepção de lealdadeeconfiança em seus pais, deacordo com Sisto eM artinelli (2004). No entanto, os adolescentes queenfrentam dificuldades no âmbito familiar, justificadas pela fase deconflitos, são merecedores deatenção (ABERASTURY; KNOBEL 1981; SERRÃ O; BALEEIRO,1999), conformecorroboram os dados desta pesquisa. 
O autoconceito social tem como enfoque tratar as relações sociais com os colegas ea maneira como a pessoa se percebenessa relação (SISTO; MARTINELLI, 2004). Os critérios se referem à avaliação de suas capacidades intel ectuais, vontade de ser igual ou melhor que os outros, desejo de ajudar os amigos e ser ajudado quando necessitar. Para Sánchez eEscribano (1999), o autoconceito influi na relação com os outros e, assim, em grande parte, está envolvido nas relações sociais da pessoa.

No autoconceito social, $40 \%$ dos adolescentes DA apresentaram bons índices, o que significa queestes sevêem de maneira positiva diante dos colegas e companheiros; $17 \%$ obtiveram pontuações medianas, mostrando quelidam com momentos de desconforto junto às pessoas e $43 \%$ obtiveram pontuações rebaixadas, o quesignifica que não serelacionam bem com os amigos esentem-seinferiores a estes.

Os dados obtidos nesta subescala indicam que os adolescentes DA que obtiveram pontuações baixas avaliam-se como não muito inteligentes, com tendência ao isolamento em situações em que percebem fracasso e se vêem sem condições de ajudar os amigos. Por outro lado, na maior parte dos casos, onde se obtiveram al tas pontuações, os adolescentes se consi deram bem, intelectual mente, comparam-se ou sentem-sesuperiores aos demais, têm vontade de ajudar as pessoas ebuscam ajuda quando precisam.

O autoconceito social, em comparação às outras áreas foi, a que apresentou pontuação mais rebaixada, demonstrando queo adolescentedeficiente auditivo possui um conceito de si não tão satisfatório no ambiente social. Tais resultados podem ser creditados à dificuldade de comunicação, geralmente ocasionada pela deficiência auditiva, de acordo com Fonseca et al. (2001), uma vez que a maioria dos relacionamentos sociais baseia-se na comunicação oral e, em algum momento, mesmo os deficientes auditivos bem oralizados sofreram interferência da surdez.

O somatório das demais áreas compreende o autoconceito geral e correspondeao que os adolescentes sentem quanto a si mesmos. Observou-seque $74 \%$ dos adolescentes DA se sentem bem, tendo um bom conceito de si mesmos; 13\% têm um autoconceito mediano e 13\% não apresentam um conceito positivo de si próprio, avaliando-se como inferiores ou piores que os outros.

Neste sentido, um elevado autoconceito indica um indivíduo que assume todas as experiências de vida, sem ignorar ou distorcer suas percepções, não mostra discrepâncias entre o real e o ideal, adota menos atitudes de defesa, é mais aberto e percebe de forma mais autêntica a realidade, com boa aceitação dos que estão ao seu redor (SÁ N CHEZ e ESCRIBAN O, 1999). Desta forma, os dados demonstram quea maioria dos adolescentes estudados obteve pontuações al tas e medianas e tende a ser pessoas adequadas aos acontecimentos da vida, levando em conta que essa subescal a éa síntese do autoconceito como um todo. 


\subsection{Q UANTO AO USO DO AASI}

Deacordo com Almei da elorio (2003), a prótese auditiva, embora seja apenas um dos componentes do tratamento do deficiente auditivo, é a pedra fundamental dos processos de habilitação e reabilitação auditiva. O questionário fechado, dirigido aos adolescentes DA, incluía perguntas sobrea aceitação do AASI, segostava do mesmo, seo consi derava importante, como o explicava às pessoas e sobre a sua percepção como deficiente auditivo, se igual ou diferente dos outros jovens.

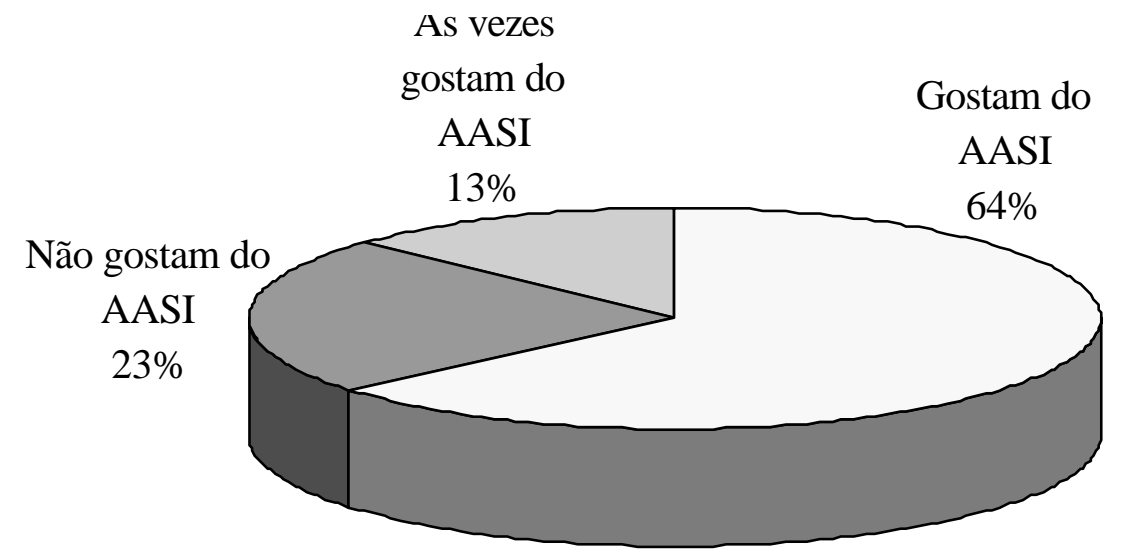

Figura 4 - Respostas dos adolescentes DA sobre o gostar do seu AASI.

As respostas ilustradas na figura 4, a respeito da primeira questão sobre gostar ou não do AA SI , mostram quea maioria dos adolescentes (64\%) respondeu quegosta do seu aparel ho, 23\% relataram não gostar dos mesmose $13 \%$ mostraramse indecisos. Evidenciou-se que os adolescentes em geral gostam do seu AASI, resultados que sugerem que os benefícios sentidos com o uso desse recurso são maiores do que os sentimentos de vergonha ou receio.

Na terceira questão, sobre a atitude do adolescented eficienteauditivo antea curiosidade al heia, foi perguntado o que ele faz quando al guém questiona sobre o AASI . A quase totalidade dos adolescentes pesquisados (90\%) respondeu que explica o que é e para que serve e apenas $10 \%$ relataram não responder às pessoas a esse respeito. Tais resultados evidenciam que a grande maioria desses adolescentes age natural menteem rel ação ao uso do AA SI, sem dificul dades para lidar com a visibilidade do mesmo. Sendo assim, é provável que não escondam o aparelho, ou a própria deficiência, atitude que estimula o uso constante desse recurso necessário à reabilitação da deficiência auditiva e, ainda que, ao utilizá-lo efetivamente, favorecem seu desenvolvimento, de acordo com Bevilacqua e Formigoni (1998). 
Em relação à constatação de Fonseca et al. (2001) sobre o AASI como um acessório que destaca o indivíduo eidentifica sua deficiência, levando o usuário a evidenciar a surdez logo no início ou a escondêla e se isolar, as respostas aqui obtidas mostram comportamentos saudáveis por parte dos adolescentes, mesmo diante da curiosidade despertada pelo aparel ho nas demais pessoas.

A pergunta seguinte, feita aos adolescentes DA, foi como eles percebem a importância do AASI. Observou-se quea metade deles (50\%), vêo AASI como importantee necessário; $27 \%$, como importante; 10\%, como necessário; $10 \%$ vêem o aparel ho com indiferença e $3 \%$ acreditam queeleédesnecessário. A partir desses achados, verifica-se que a mai oria dos adolescentes do estudo, ou seja, 87\%, têm consciência do significado do aparel ho deamplificação em sua vida eessa percepção favorece não apenas o uso efetivo do mesmo, mas também a sua conservação e manutenção.

Em relação à percepção de si como deficiente auditivo, $44 \%$ dos adolescentes responderam que se vêem iguais aos outros jovens e um número muito próximo, 40\%, respondeu quesevêdiferentedos demais, restando $13 \%$ que não souberam definir como se vêem e $3 \%$ de indecisos. As respostas indicaram uma semel hança entre o número deadolescentes que se vêem iguais ou diferentes dos demais jovens. É provável queaqueles que se vêem como diferentes vivenciem essa fase da vida com certa dificuldade, de acordo com o relato de Fonseca et al. (2001), de que este é um período da vida em que os jovens buscam a homogeneização, desejando se tornar parecidos para fazerem parte do grupo.

O questionário semi-aberto, aplicado aos pais, contemplou as situações avaliadas também com o adolescente DA, aprofundando as questões do uso do AASI, em relação ao tempo deadaptação, às dificuldades encontradas, ao uso diário, às queixas e percepções pessoais acerca do aparel ho e da deficiência auditiva.

Observou-se que $97 \%$ dos adolescentes DA estão adaptados há mais de 3 anos e apenas 3\% há menos de um ano. Metade dos pais respondeu positivamente quanto ao filho ter enfrentado dificuldades na fase deadaptação ao uso do $\mathrm{AASI}$, enquanto que os outros $50 \%$ não evidenciaram dificuldades. $A$ adaptação é um período que exige paciência, já que se trata de uma prótese, al go novo eestranho à pessoa emesmo assim houveum equilíbrio entre os adolescentes DA que enfrentaram ou não dificuldades, na visão deseus pais.

Conforme A Imeida e Iorio (2003), a adaptação da prótese auditiva é uma das condições fundamentais para que o deficiente auditivo desenvolva seu potencial, desdequeeleutilize plenamenteo aparel ho, isto é, em todas as horas do dia. As respostas dos pais quanto ao período de uso diário do aparelho pelo adolescente possibilitaram identificar quea maioria, ou seja, 71\% dos sujeitosfazem uso do mesmo durante o dia todo; $13 \%$ só no período da manhã; $3 \%$ usam de manhã e à noite; 3\% de manhã e à tarde; 3\% apenas à tarde e 7\% não usam o aparelho. A figura 5 sintetiza esses dados, mostrando quea grandemai oria usa o 
aparelho em mais de dois períodos por dia, favorecendo a comunicação que promova o desenvolvimento e os relacionamentos.

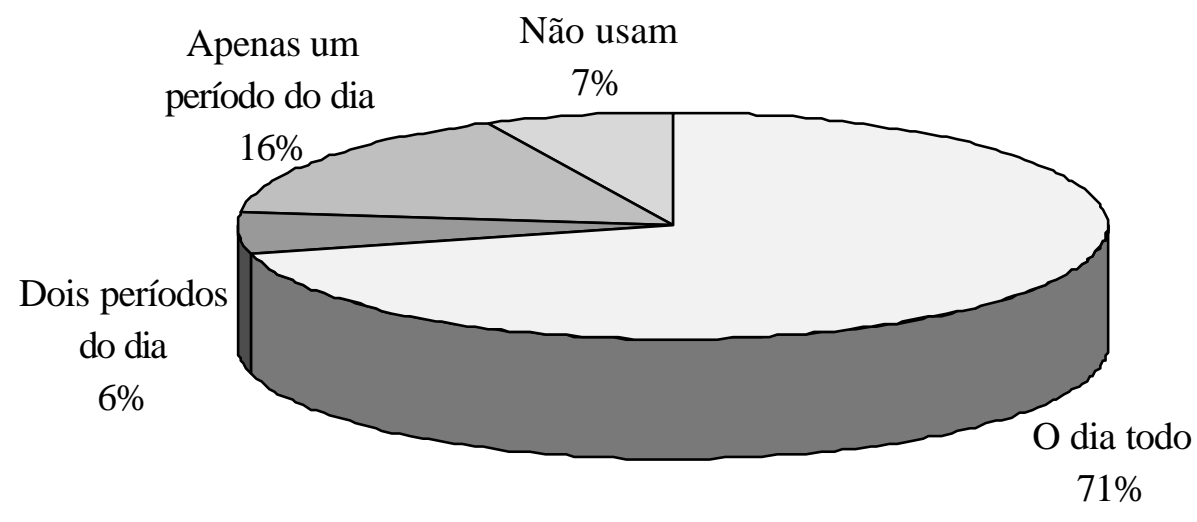

Figura 5 - Respostas dos pais sobre o uso diário do AASI pelos adolescentes DA

Para Bevilacqua e Formigoni (1998), o AASI, quando bem adaptado, passa a fazer parte do esquema corporal do indivíduo deficiente auditivo e, nessa condição, o aproveitamento tende a ser máximo, uma vez queo aparelho somente éretirado para tomar banho edormir.

Tendo em vista a importância da aceitação e uso constante do AASI, uma das questões submetidas aos pais buscou identificar situações do dia-a-dia em que os adolescentes DA serecusam a usar o aparelho. Os resultados mostraram que $37 \%$ deles não recusam o aparel ho e $63 \%$ se recusam a usá-lo em determinadas situações, tais como em passeios (57\%) sendo citados, em dois casos, os finais de semana ea presença deal guém do sexo oposto; $11 \%$ em casa; $17 \%$ em ambiente de muito ruído e $15 \%$ apontaram outros motivos inconstantes, como chuva, zumbido e medo de perder.

Essas respostas sugerem não aceitação e conflito em eventos sociais. As considerações a serem feitas podem remeter à exposição desnecessária, pois não se trata de situação específica de aprendizado, como escola ou fonoterapia. Então, o aspecto defendido por Fonseca et al. (2001) sobre o conflito gerado diante deuma condição especial queéaquilo queo aparel ho representa, podejustificar a recusa nos momentos de passeio. Quanto à recusa em situação de ruído intenso, é possível queo motivo seja o desconforto causado pela amplificação queo aparelho proporciona.

Essa questão, complementada com as respostas sobre as queixas do filho quanto ao tamanho do AASI, o que o torna mais ou menos visível, foi respondida negativamentepela maior partedos pais (64\%). Outros $33 \%$, entretanto, 
expressaram que os filhos se queixam freqüentemente do tamanho do aparelho, enquanto 3\% manifestaram que essa queixa ocorre ocasionalmente.

A percepção dos pais à deficiência auditiva do filho foi avaliada em uma pergunta abordando a opinião deles sobre o uso do aparelho. Dos pais entrevistados, $57 \%$ consideram ótimo ou bom o filho usar AASI; $20 \%$ entendem o aparelho como necessi dade, expressando que têm de aceitar, sendo que um deles posicionou o uso do aparel ho como uma "cruz"; 17\% relataram indiferença, por não atrapalhar e6\% não souberam responder.

A maneira positiva como a maior parte dos pais vêo fato do filho usar o AASI tem grandeinfluência no uso efetivo desse recurso pelo indivíduo deficiente auditivo, além de refletir o grau deaceitação dessa limitação. A utores como Campos (1990) têm relatado a importância desse fator ser levado em conta no processo de adaptação. Como conseqüência, a sensação do usuário, em relação ao aparel ho eà maneira como o meio social enxerga esse dispositivo, interfereno uso freqüentee na boa adaptação ao AASI .

Dando seqüência a essa análise, a percepção dos pais aos sentimentos dos adolescentes DA, em relação ao uso do AASI eà sua condição foi investigada. Foi questionado aos pais como eles consideram que o filho se sente usando o aparel ho, obtendo-se, em $64 \%$ das respostas, afirmações positivas, que o filho se sente bem, normal, tranqüilo. Outras $37 \%$ de respostas foram negativas, com os pais expressando que o filho não gosta, tem vergonha, se sentediferente, nervoso, irritado. Em dois casos, os pais responderam que o filho às vezes se incomoda $e$ que com o molde de silicone se sentirá melhor (6\%), e um último caso não foi respondido (3\%).

Na questão como o adolescentese vêcomo deficienteauditivo, obtevese o maior número de respostas: $83 \%$ dos pais acreditam que seu filho se vê de maneira normal, positiva, indiferente enunca sequeixou por ser deficiente; outros 10\% deram respostas distintas: que o filho sevêdiferente, não se vêmuito "normal", ou tenta ser igual aos demais eem $7 \%$ dos casos os pais não souberam responder a questão.

As respostas às questões mostram que os pais têm pontos de vista positivos sobre o filho adolescente DA e seu AASI, não acreditando em grandes conflitos. Ainda assim, muitos autores, dentre os quais, Serrão e Baleeiro (1999), consideram que a adolescência é um período que merece atenção e cuidado, principalmente dos pais, educadores e profissionais de saúde, ressaltando, no entanto, que o reconhecimento dessa fase da vida sob um prisma sombrio eobscuro podelimitar práticas potencializadoras. 


\subsection{Sobre o autoconceito e a Rela Ção com o uso do AASI Pelo adolescente deficiente AUDITIVO}

A análisedos resultados permitesupor quepara uma partedos sujeitos, o autoconceito social apresentou-serebaixado em relação aos demais. Esseachado pode estar relacionado ao fato da maioria (63\%) dos adolescentes deficientes auditivos não utilizar o AASI em situações específicas, como passeios, queenvolvem a condição de estarem expostos a serem diferente dos demais.

A Imeida elorio (2003), sobre o convívio social, esclarecem que para o portador de deficiência auditiva, dificuldades devido aos ambientes ruidosos, às situações de conversação com grupos de pessoas, ao constrangimento em pedir para o interlocutor repetir ou falar mais al to etornar-semotivo dezombaria ou de desprezo, levam o indivíduo ao isolamento.

Assim, as dificuldades na comunicação interferem diretamente na relação do deficiente com os demais e se somam à vergonha, entre outros sentimentos negativos, que interferem no autoconceito.

Também podemos associar os bons índices do autoconceito familiar às respostas dadas pel os pais na entrevista semi-aberta, na qual, a maioria consi dera positivo o filho usar o AASI. Além disso, o uso diário, em período integral, pode estar relacionado a esse fato, já queà família éatribuído um papel fundamental no uso do AASI. Assim, sentir que o uso do aparelho é bem aceito em casa, é incentivador para queo adolescenteo use efetivamente.

Quanto ao autoconceito escolar, as respostas do questionário que demonstraram que os pais têm um bom conceito de seu filho deficiente auditivo, então relacionadas ao bom desempenho na subescala familiar, pois havendo o apoio dos pais, as dificuldades escolares serão amenizadas.

Os bons índices na subescal a de autoconceito pessoal significam queo adolescentese vê de bem consigo eesses resultados estão relacionados às respostas dos questionários a eles aplicados, segundo os quais, $64 \%$ dos participantes gostam de seu aparelho, isto é, pessoalmente têm bons sentimentos sobre si e isto reflete em sua relação com o AASI.

A otimista visão desi, queos adolescentes deficientes auditivos podem apresentar, precisa ser reconheci da eimplementada nas estratégias de prevenção, promoção da saúde, bem como em outros campos, como a educação, os relacionamentos sociais e o desenvolvimento emocional. De modo geral, os resultados indicam que os adolescentes usam egostam do AASI , o quenão significa que não existam conflitos, mas que estes podem ser superados, principalmente com o suportefamiliar e profissional. 


\section{Conclusão}

Os dados obtidos eavaliados mostram que os adolescentes deficientes auditivos pesquisados reagem natural mente ao fato de usar AASI. Se a maioria deles faz uso do AASI há mais de três anos, o aparelho já foi incorporado, o que contribui para um desenvolvimento emocional saudável.

A condição do acompanhamento multi/ interdisciplinar especializado ao qual os participantes e seus pais têm acesso, proporciona avaliações e continuidade da adaptação adequada aos AASI, bem como suporte na área psicossocial, contribuindo também para o uso do aparelho.

Uma menor porcentagem de adolescentes deficientes auditivos não usa e não gosta de seu AASI, resultado este relacionado ao pequeno número de adolescentes que possui autoconceito desfavorável.

Assim, o uso efetivo do AASI pelos adolescentes com deficiência auditiva está diretamente relacionado às boas condições de seu autoconceito.

Para aprofundamento do tema desta pesquisa, estudos podem ser conduzidos, a fim deidentificar o quecaracteriza a vida dos adolescentes deficientes auditivos queapresentam altas ebaixas pontuações, ou seja, autoconceitos positivos ou negativos. Tais informações podem sugerir intervenções para essa população e orientações aos pais e profissionais que atuam na área.

Ainda, em relação aos adolescentes deficientes auditivos que se vêem diferentes dos demais, podem ser levantados os motivos dessa percepção acerca de si mesmos, uma vez que podem não estar relacionados diretamente à sua condição auditiva eao uso do AASI .

\section{Referências}

ABERASTURY, A.; KNOBEL, M. A dolescência normal. Porto Alegre: Artes Médicas, 1981. ALMEIDA, K. elORIO, M.C.M.P róteses auditivas: fundamentos teóricos eaplicações clínicas. 2. ed. São Paulo: Lovise, 2003.

BEVILACQUA, M.C.; FORMIGONI, G.M.P. A udiologia educacional: uma opção terapêutica para a criança deficiente auditiva. Carapicuíba: Pró-Fono, 1998.

BRANDEN, N . A uto-estima: como aprender a gostar de si mesmo. São Paulo: Saraiva, 2000.

CAMPOS, L.C.S. Estigma na adaptação de aparel ho de amplificação sonora individual em adultos. 1990. 221f. Dissertação (M estrado em Psicologia) - U niversidadedeSão Paulo, São Paulo, 1990. FONSECA, V.R.J.R.M. (Org.) et al. Surdez e deficiência auditiva: a trajetória da infância à idade adulta. São Paulo: Casa do Psicólogo, 2001.

MOTTI, T.F.G. A rotina de um centro de referência em deficiência auditiva: perspectiva de pais e profissionais. 2000. 216 f. Dissertação (M estrado em Educação Especial) - Universidade Federal de São Carlos, São Carlos, 2000.

SÁN CHEZ, A.V.; ESCRIBANO E.A. M edição do autoconceito. tradução de Cristina Murachco. Bauru: EDUSC, 1999. 
ZUGLIANI, A. P.; MOTTI, T. F. G.; CASTANHO, R. M.

SERRÃO, M.; BALEEIRO, M.C. A prendendo a ser e a conviver. São Paulo: FTD, 1999.

SISTO, F.F.; MARTINELLI, S.C. Escala de autoconceito infanto-juvenil (EAC-IJ).São Paulo: Vetor Editora Psico-pedagógica, 2004.

TAMAYO, A. EFA: Escala Fatorial de Autoconceito. A rquivos Brasileiros de Psicologia, Rio deJaneiro, v. 33, n. 4, p. 87-102, 1981.

\section{Quadro 1- Questionário - A dolescente}

\begin{tabular}{|lll|}
\hline 1) Você gosta do seu AASI? & () Sim ( ) Não ( ) As vezes \\
\hline 2) Como você se vê como deficiente auditivo? & ( ) Igual aos outros jovens \\
& ( ) Diferente \\
& ( ) Não sabe definir \\
3) Quando alguém pergunta sobre o seu AASI o & ( ) Tentros explicar o que é e para que serve \\
& ( ) Não responde \\
& ( ) Outros \\
4) Para você o aparelho é: & ( ) Importante \\
& ( ) Importante e Necessário \\
& ( ) Necessário \\
& () Indiferente \\
& ( ) Desnecessário \\
& () Outros \\
\hline
\end{tabular}

\section{Quadro 2 - Entrevista - Pais}

\begin{tabular}{|c|c|}
\hline 1) Há quanto tempo seu filho faz uso do AASI? & $\begin{array}{l}\text { ( ) Menos de } 1 \text { ano } \\
\text { ( ) De } 1 \text { ano e } 1 \text { mês a } 2 \text { anos } \\
\text { ( ) De } 2 \text { anos e } 1 \text { mês a } 3 \text { anos } \\
\text { ( ) Mais de } 3 \text { anos }\end{array}$ \\
\hline \multicolumn{2}{|l|}{ 2) Seu filho teve dificuldade para adaptação? } \\
\hline 3) Seu filho usa o AASI: & $\begin{array}{l}\text { ( ) O dia todo } \\
\text { ( ) Manhã } \\
\text { ( ) Tarde } \\
\text { ( ) Noite }\end{array}$ \\
\hline \multicolumn{2}{|l|}{ 4) Seu filho se queixa do tamanho do AASI? } \\
\hline \multicolumn{2}{|l|}{ 5) O que você acha de seu filho usar AASI? } \\
\hline $\begin{array}{l}\text { 6) Existe alguma situação que seu filho se recusa a } \\
\text { usar o aparelho? }\end{array}$ & 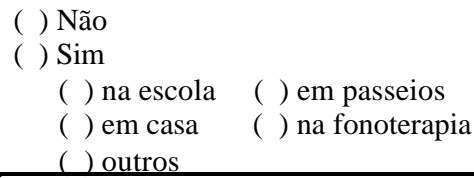 \\
\hline
\end{tabular}

Recebido em 22/ 01/ 2007

A provado em 30/ 04/ 2007 